\title{
Temperature Optimization by Electrochemical Method for Improving Antioxidant Compound Extraction Efficiency from Origanum vulgare L. and Its Application in a Bread Production
}

\author{
Anna Mikołajczak ${ }^{1}$, Marta Ligaj ${ }^{1}\left[\right.$ and Joanna Kobus-Cisowska ${ }^{2, *}(\mathbb{D}$ \\ 1 Department of Non-Food Products Quality and Packaging Development, Poznan University of Economics \\ and Business, 61-875 Poznan, Poland; anna.maria.mikolajczak@gmail.com (A.M.); \\ marta.ligaj@ue.poznan.pl (M.L.) \\ 2 Department of Gastronomy Sciences and Functional Food, Poznan University of Life Sciences, \\ 60-637 Poznan, Poland \\ * Correspondence: joanna.kobus-cisowska@up.poznan.pl
}

\section{check for}

updates

Citation: Mikołajczak, A.; Ligaj, M.; Kobus-Cisowska, J. Temperature Optimization by Electrochemical Method for Improving Antioxidant Compound Extraction Efficiency from Origanum vulgare L. and Its Application in a Bread Production. Sustainability 2022, 14, 2801.

https://doi.org/10.3390/su14052801

Academic Editors: Ivan Savic and Ivana Savic Gajic

Received: 10 January 2022

Accepted: 25 February 2022

Published: 28 February 2022

Publisher's Note: MDPI stays neutral with regard to jurisdictional claims in published maps and institutional affiliations.

Copyright: (C) 2022 by the authors. Licensee MDPI, Basel, Switzerland. This article is an open access article distributed under the terms and conditions of the Creative Commons Attribution (CC BY) license (https:// creativecommons.org/licenses/by/ $4.0 /)$.

\begin{abstract}
This study aims to evaluate the effect of extraction temperature on the electrochemical activity of antioxidant compounds in oregano extract and its application in a bread production. Temperature optimisation was performed by determining the electrochemical index (EI), calculated on the parameters of individual peaks observed on the square wave voltammograms (SWV). The highest value of EI $(2.5758 \mu \mathrm{A} / \mathrm{V})$ was observed at $85^{\circ} \mathrm{C}$ for the oregano extract. The composition of several types of bread with oregano extract or dried oregano leaves was then proposed. To specify bread samples, both newly prepared and during their storage, their antioxidant properties were determined using FRAP (Ferric Reducing Antioxidant Power) and CUPRAC (Cupric Reducing Antioxidant Capacity) methods. The study revealed that the addition of extract from oregano or oregano leaves increased the antioxidant compounds content in the bread from $30 \%$ to more than $138 \%$ compared to the control bread samples. The performed sensory evaluation of the bread samples revealed their high acceptability. It was found that the stored bread with oregano leaves changed sensory qualities to a lesser extent compared to the bread with oregano extract.
\end{abstract}

Keywords: aromatic herbs; oregano; voltammetry; healthy food; functional food; sensory attributes

\section{Introduction}

Herbs and herbal preparations contain beneficial active ingredients such as: essential oils, tannins, glycosides, flavonoids, terpenes, mucilage, and organic acids. Plant extracts obtained from herbs and spices are a valuable source of bioactive compounds that may have the desired effect on biochemical processes in the human body. Hence, they can contribute to better health, both in terms of preventing and supporting the treatment of diseases. The increasing intake of dietary antioxidants may help to maintain an adequate antioxidant status and thus the normal physiological functions of a living system. This requires focusing on exploring natural sources of compounds with unique health-enhancing properties that can provide high functionality to food. This is especially important in terms of protecting the body from damage due to oxidative stress. The exposure to elevated levels of free radicals is responsible for accelerating aging-related processes, leads to damage to numerous cellular structures, and is particularly dangerous for its genotoxic effects $[1,2]$.

Oregano is a plant belonging to the aromatic herbs of the Labiatae family and is a source of antioxidant compounds such as phenolic acids, flavonoids, tocopherols, and essential oils including carvacrol, thymol, and phytosterols. There are literature data concerning the expectorant, disinfectant, anti-diarrhoeal, diuretic, antispasmodic, carminative, or detoxifying properties of oregano [3,4]. Therefore, the active compounds contained in Origanum vulgare L. exhibit an extremely wide spectrum of health-enhancing effects on the 
human body. In gastronomy, oregano is widely used as a seasoning for roasted, baked, and fried dishes or salads. In the present study, due to oregano's common use in diet and the possibility of developing an acceptable sensory composition, several types of bread containing the leaf oregano extract or dried oregano leaves were proposed.

Square wave voltammetry (SWV) has been used to study the electrochemical properties of the antioxidants in plant materials, food, and their extracts [5-8]. This technique provides a fast and simple way to find the optimal conditions for obtaining extracts from plant material and can be an alternative to more complicated and time-consuming chemical and chromatographic methods, such as HPLC and GC. Electrochemical methods do not allow the determination of the detailed qualitative and quantitative composition of individual components of the tested extracts, but they can be used to estimate the total antioxidant activity of the studied samples. Thus, this study was proposed to use the SWV technique to determine the optimal temperature for the extraction of antioxidants from oregano leaves using the electrochemical index (EI). Then, the effect of adding oregano extracts obtained at optimal temperature in different ratios to bread was investigated and the effect of these on bread quality during storage was evaluated. Bread quality was evaluated by antioxidant activity and sensory analysis.

\section{Materials and Methods}

\subsection{Chemicals}

Graphite powder, mineral oil, and neocuproine (2,9-dimethyl-1,10- phenanthroline) were from Sigma (Tokyo, Japan). 2,4,6-tris(2-pyridyl)-(S)-triazine was purchased from Fluka (Buchs, Switzerland). All other chemicals were from POCH (Gliwice, Poland).

\subsection{Oregano Extract Preparation}

The extraction of antioxidants from oregano (Origanum vulgare L.) leaves was performed according to a previously published protocol [9]. In order to establish the optimal temperature, the extraction was carried out at $80,85,90,95$, and $100{ }^{\circ} \mathrm{C}$.

\subsection{Electrochemical Conditions}

Electrochemical measurements were carried out using a PGSTAT12 potentiostat with GPES software, version 4.9 (Eco Chemie, Utrecht, The Netherlands). Electrochemical testing was conducted in a system that consists of three electrodes: carbon paste working electrode, $\mathrm{Ag} / \mathrm{AgCl}(3 \mathrm{M} \mathrm{KCl})$ as reference electrode, and platinum wire as auxiliary electrode. The working electrode was prepared independently, while both auxiliary and reference electrodes were purchased from Mineral (Poland). The carbon paste electrode was made from graphite powder and mineral oil mixed in a ratio of 70:30 $(w / w)$. The prepared paste was placed in a Teflon tube with a diameter of $1 \mathrm{~mm}$ and length of $5 \mathrm{~mm}$. The electrical connector was a copper wire. Regeneration of the working electrode surface after each use consisted of rubbing off the top layer of paste on a hard blotting paper, refilling it with a new portion of paste, and smoothing the surface on a frosted microscope slide. The electrodes were placed in a stand, resulting in obtaining both adequate distances between the electrodes and their constant immersion depth in a $1 \mathrm{~mL}$ measuring vessel, the contents of which were stirred at $200 \mathrm{rpm}$ using a magnetic stirrer.

The SWV was used as a measurement technique. Each measurement included the following steps:

1. Carbon electrode surface conditioning: $60 \mathrm{~s}(+1.7 \mathrm{~V}), 0.05 \mathrm{M}$ phosphate buffer with $0.01 \mathrm{M} \mathrm{KCl}(\mathrm{pH} 7.0)$.

2. Carbon electrode immersion in a cell containing the tested oregano extract (extracted at $80,85,90,95$, and $100^{\circ} \mathrm{C}$, respectively) and $0.05 \mathrm{M}$ phosphate buffer with $0.01 \mathrm{M}$ $\mathrm{KCl}(\mathrm{pH} \mathrm{7.0)}$ at a volume-to volume ratio of 1:1 for $5 \mathrm{~min}$.

3. SWV measurement in the same cell.

The parameters of SWV measurements were: the amplitude of $40 \mathrm{mV}$, frequency of $50 \mathrm{~Hz}$, and step potential of $5 \mathrm{mV}$. The measurements were performed in triplicate. 


\subsection{Electrochemical Index}

On the base of volammograms obtained for the analysed extracts, the electrochemical index (EI) was calculated using the equation proposed by Lino et al. [10]:

$$
\mathrm{EI}=\frac{I_{p a 1}}{E_{p a 1}}+\frac{I_{p a 2}}{E_{p a 2}}+\frac{I_{p a 3}}{E_{p a 3}}
$$

In which $I_{p a 1}, I_{p a 2}$, and $I_{p a 3}$ expresses the value of the current of the individual peaks and $E_{p a 1}, E_{p a 2}$, and $E_{p a 3}$ expresses its position on the potential axis.

\subsection{Bread Preparation}

An amount of $1000 \mathrm{~g}$ of the mixture from which the dough was prepared contained $600 \mathrm{~g}$ of tap water in accordance with standards for drinking water parameters. In the present study, bread was made using recipe modifications - the addition of oregano leaf extract at $0.1 \%, 0.4 \%$, or $0.7 \%$ compared to the dry weight of dough ingredients (samples: $\mathrm{E} 1, \mathrm{E} 2$, and E3, respectively). Moreover, bread was made using crushed oregano leaves at $2 \%, 3 \%$, or $4 \%$ (samples: L2, L3, and L4, respectively). KC was the control without the addition of oregano. The bread ingredients, in addition to the oregano extract or dried oregano leaves, included wheat flakes $(2.7 \%)$, corn flour $(4 \%)$, millet $(1 \%)$, broken soya beans $(2 \%)$, soybean flour $(1 \%)$, wheat malt flour $(1 \%)$, lactic acid $(0.1 \%)$, citric acid $(0.1 \%)$, sugar (1\%), emulsifier E 472 - mono and diglycerides of fatty acids ( $2 \%)$, rapeseed lecithin $(2 \%)$, stabiliser E 466 - sodium carboxymethyl cellulose ( $2 \%)$, ascorbic acid $(2 \%)$, rye flour $(26 \%)$, yeast $(3 \%)$, low-sodium salt $(1 \%)$, and wheat flour in an amount complementary to $100 \%$ bread composition.

Bread was tested immediately after baking and after 5 days of storage. Bread samples were stored in a closed foil packet. Stored bread with oregano extract was determined as E1S, E2S, and E3S and L2S, L3S, and L4S (bread with dried oregano leaves), respectively. The stored control sample was determined as KCS. The studied bread was dried at $60{ }^{\circ} \mathrm{C}$ to a constant mass. Then, it was ground using a Retsch GM200 laboratory mill (5000 rpm/s pulse for $10 \mathrm{~s}$ ). Such prepared samples were extracted via the accelerated solvent extraction (ASE) technique using a Dionex ASE 350 extractor (Thermo Fisher Scientific, Waltham, MA, USA). The extraction was performed three times: first with $60 \%$ methanol at $20^{\circ} \mathrm{C}$, then twice with distilled water at $85^{\circ} \mathrm{C}$. The results are shown as the absorbance value.

\subsection{Antioxidant Potential Analysis of Bread Samples}

The reducing properties (FRAP) were determined according to the method described by Hanafy et al. [11]. The method is based on the reduction of the ferric tripyridyl triazine $\left(\mathrm{Fe}^{3+}\right.$-TPTZ) complex to the ferrous tripyridyl triazine $\left(\mathrm{Fe}^{2+}\right.$-TPTZ), with a light absorption maximum at $593 \mathrm{~nm}$. The complex stability depends on $\mathrm{pH}$ and optimal conditions occur at $\mathrm{pH} 3.6$, which is obtained by the addition of acetate buffer. The calibration curve was prepared using $0.51 \mathrm{mg}$ Trolox dissolved in $1 \mathrm{~mL}$ of DDI water (stock solution diluted to obtain 20 standard solutions in the range of $0.0255-0.51 \mathrm{mg}$ Trolox $/ \mathrm{mL}$ ).

On the other hand, the CUPRAC method involves the reaction of the complex of neocuproine and copper (II) chloride with antioxidant compounds, during which the phenolic groups of polyphenols are oxidised to quinones, and the blue-coloured complex of neocuproine and copper (II) ions is reduced to a yellow-coloured complex of neocuproine and copper (I) ions [12]. A mixture containing equal volumes of acetate buffer $(\mathrm{pH}=7.0)$, $7.5 \mathrm{mM}$ neocuproine solution in $96 \%$ ethanol, and $10 \mathrm{mM}$ aqueous $\mathrm{CuCl}_{2}$ solution was prepared to determine the CUPRAC antioxidant activity. Fifty (50) $\mu \mathrm{L}$ of standard or studied extracts at a concentration of $0.312 \mathrm{mg} / \mathrm{mL}$ were added to the wells of the 96-well plate, followed by $150 \mu \mathrm{L}$ of the CUPRAC mixture. The background was a mixture of $50 \mu \mathrm{L}$ of distilled water and $150 \mu \mathrm{L}$ of the CUPRAC mixture. The plate was incubated for $30 \mathrm{~min}$. in a dark place. The experiment was conducted at room temperature. The absorbance was measured at $\lambda=450 \mathrm{~nm}$, and quercetin was used as the antioxidant standard $(0.23 \mathrm{mg}$ of 
quercetin dissolved in $0.5 \mathrm{~mL}$ and $0.5 \mathrm{~mL}$ of acetonitrile), diluted into 20 standard solutions $(0.0175-0.35 \mathrm{mM} / \mathrm{L}, 0.015 \mathrm{~mL})$ used as described above.

\subsection{Sensory Analysis of Bread with Oregano}

The study was conducted in a properly designed and equipped sensory analysis laboratory. Sensory profiling was conducted by a trained team of 15 people. Firstly, the descriptors of colour, consistency, taste, and odour were designated and defined. The intensity of each descriptor was determined by the assessors using a $10 \mathrm{~cm}$ linear scale with appropriate boundary descriptions. Bread samples of approximate weight of $30 \mathrm{~g}$ were dispensed in pre-prepared and coded plastic containers $(50 \mathrm{~mL})$ covered with lids. Unsweetened black tea at $45^{\circ} \mathrm{C}$ was dispensed along with the samples as a taste neutraliser.

\subsection{Statistical Analysis}

The comparisons of the mean values of the studied characteristics were made using the analysis of variance (ANOVA) for factor-related systems with varying numbers of observations, and intergroup differences were assessed using the Tukey's test or the Spjotvoll's test (an extended Tukey's test for unequal sample sizes). Meeting the assumptions of these results was also verified. Statistical inference was performed at a significance level of $\alpha=0.05$. Appropriate nonlinear (exponential) regression equations were determined to examine the shape and direction of the relationships between the studied activities. Moreover, the principal component analysis (PCA) method was used.

\section{Results and Discussion}

\subsection{Electrochemical Activity of Oregano Extract}

Oregano extracts obtained under varying temperature conditions (from $80{ }^{\circ} \mathrm{C}$ to $100^{\circ} \mathrm{C}$ ) were subjected to electrochemical testing to evaluate the content of electroactive compounds. As is commonly known, temperature is one of the primary factors that affect the extraction efficiency. Compounds with antioxidant properties undergo electrochemical reactions that can also occur at electrodes under the influence of an applied potential. Therefore, voltammetric techniques can be used for the measurement of electroactive compounds' concentration in studied samples. The SWV, which is one of the highly sensitive pulse techniques, was used for the measurements. This very sensitive technique makes it possible to determine analytes at a very low concentration below $10^{-8} \mathrm{M}$ [13]. Based on the measurements, it was possible to determine the optimal temperature for extracting antioxidants from the oregano extract. Figure 1 shows the electrochemical signals in the voltammogram of the oregano extracts obtained at $85^{\circ} \mathrm{C}$.

Electrochemical measurements revealed the presence of three SWV signals located in the $+0.42,+0.86$, and $+1.065 \mathrm{~V}$ regions. The signal in the $+0.42 \mathrm{~V}$ region had the highest values of current.

Table 1 compares the electrochemical parameters determined for the studied extracts based on three replicate measurements. The RSD (Relative Standard Deviation) value for successive replicate measurements ranged from $1 \%$ to $5 \%$. Considering the values of the current and potential of the individual peaks visible on the SW voltammograms, the electrochemical index (EI) was calculated for each extract. The peak current is directly proportional to the antioxidant activity, while the peak potential is inversely proportional, therefore the calculation of EI provides a useful parameter of antioxidant power of the analysed samples [14]. The relationship between the EI value and the applied temperature of extraction is shown in Figure 2. 


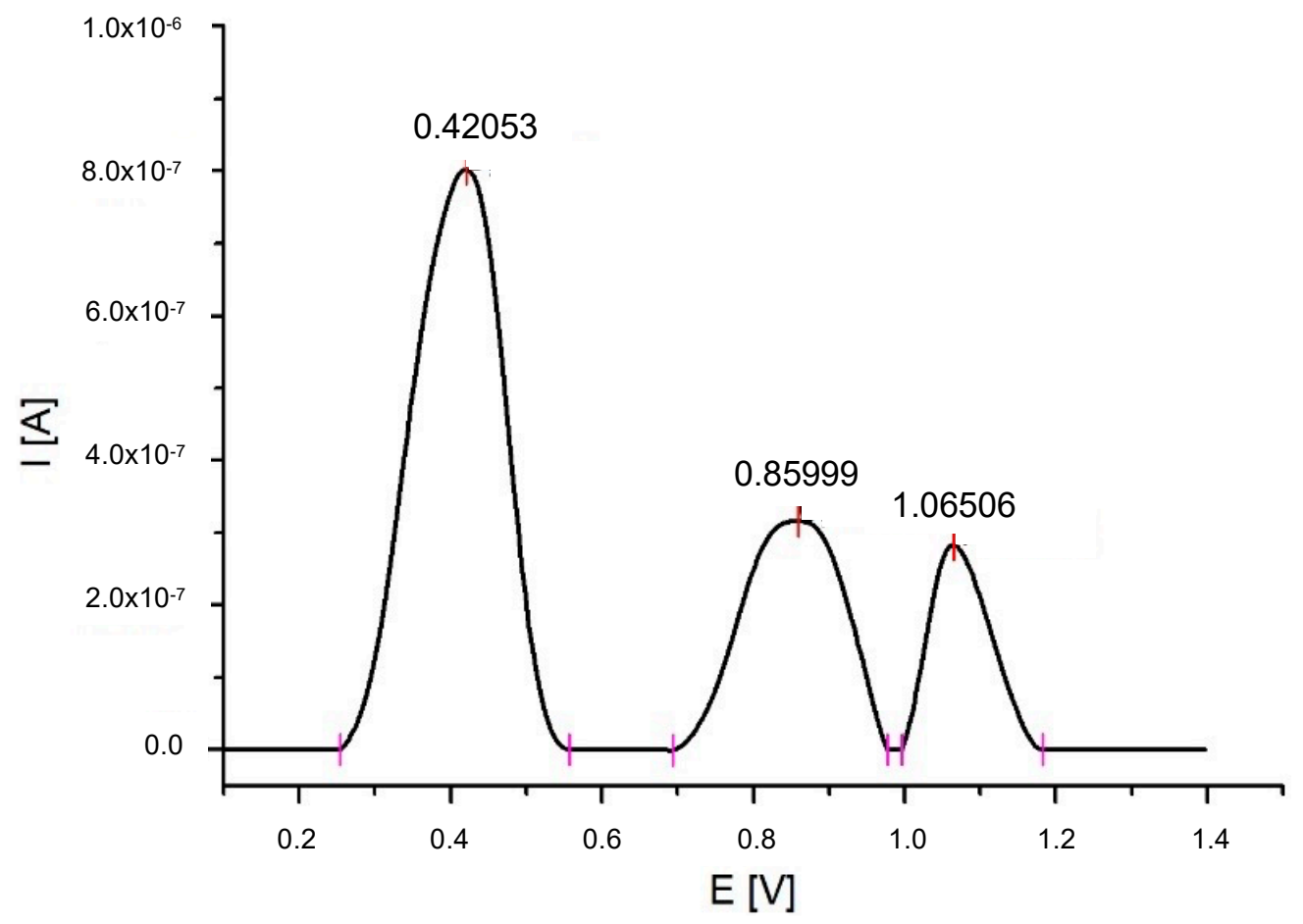

Figure 1. Square wave voltammogram of $0.125 \%$ oregano extract in $0.05 \mathrm{M}$ phosphate buffer with $0.01 \mathrm{M} \mathrm{KCl}, \mathrm{pH}$ 7.0. SWV parameters: step potential of $5 \mathrm{mV}$, amplitude of $40 \mathrm{~V}$, and frequency of $50 \mathrm{~Hz}$

Table 1. The electrochemical parameters determined for oregano extracts.

\begin{tabular}{ccccc}
\hline $\begin{array}{c}\text { Extraction } \\
\text { Temperature }\end{array}$ & $\begin{array}{c}\text { Peak Potential } \\
\mathbf{E}_{\mathbf{p}}[\mathbf{V}]\end{array}$ & $\begin{array}{c}\text { Peak Current } \\
\mathbf{I}[\boldsymbol{\mu A}]\end{array}$ & $\begin{array}{c}\text { Peak Area } \\
\mathbf{E}_{\mathbf{P}} \times \mathbf{I}[\mathbf{V} \times \boldsymbol{\mu A}]\end{array}$ & $\begin{array}{c}\text { Total Peak Area } \\
{[\mathbf{V} \times \boldsymbol{\mu} \mathbf{A}]}\end{array}$ \\
\hline \multirow{3}{*}{$80^{\circ} \mathrm{C}$} & 0.42 & 0.745 & 0.243 & \\
& 0.86 & 0.298 & 0.171 & 0.495 \\
& 1.065 & 0.256 & 0.081 & \\
$85^{\circ} \mathrm{C}$ & 0.42 & 0.805 & 0.273 & \\
& 0.86 & 0.323 & 0.1969 & \\
& 1.065 & 0.302 & 0.106 & \\
$90{ }^{\circ} \mathrm{C}$ & 0.42 & 0.764 & 0.262 & \\
& 0.86 & 0.312 & 0.185 & \\
\hline & 1.065 & 0.275 & 0.098 & \\
& 0.42 & 0.708 & 0.238 & \\
& 0.86 & 0.267 & 0.154 & \\
& 1.065 & 0.228 & 0.075 & \\
\hline
\end{tabular}

The data indicated that to obtain the maximum content of electroactive compounds of oregano extract, the optimal temperature of the extraction procedure was $85^{\circ} \mathrm{C}$. According to the literature data, the efficiency of polyphenol extraction is better at lower temperatures $[15,16]$. It should be emphasized that electrochemical measurements do not allow polyphenols to be distinguished from other compounds with antioxidant activity that are likely to be better extracted at higher temperatures. Clearly, the extract obtained at $85^{\circ} \mathrm{C}$ had higher electrochemical activity, expressed as the total area of SWV signals, and the EI determined from it. The total area of SWV signals was $0.569 \mathrm{~V} \times \mu \mathrm{A}$, while the EI was 2.5758. For extraction performed at $100{ }^{\circ} \mathrm{C}$, the EI had the lowest value of 1.9893 . There are 
numerous papers concerning the optimisation of temperature for extracting compounds with antioxidant activity from plant material. For example, similar results were obtained by Khattak et al. [17], who found that among the various temperatures used (from 75 to $\left.100{ }^{\circ} \mathrm{C}\right), 85^{\circ} \mathrm{C}$ was the optimum temperature for total phenolic content (TPC) and total flavonoid content (TFC) in the obtained extracts from holy basil (Ocimum tenuiflorum) and onion (Allium fistulosum). Additionally, this temperature of extraction of phenolic compounds from irradiated olive wastes was found to be optimal during the study conducted by Madureira et al. [18]. However, it should be emphasised that the optimum temperature of extraction depends on the plant material and applied methodology. A detailed calculation of the effect of extraction temperature and used environment on the phytochemical and bioactive properties of Ocimum gratissimum extracts was presented in the study by Onyebuchi and Kavaz [15]. It is well known that, apart from temperature, other factors, including mainly the used extractants, have a significant impact on the extraction efficiency, as described by Vieira et al. [16].

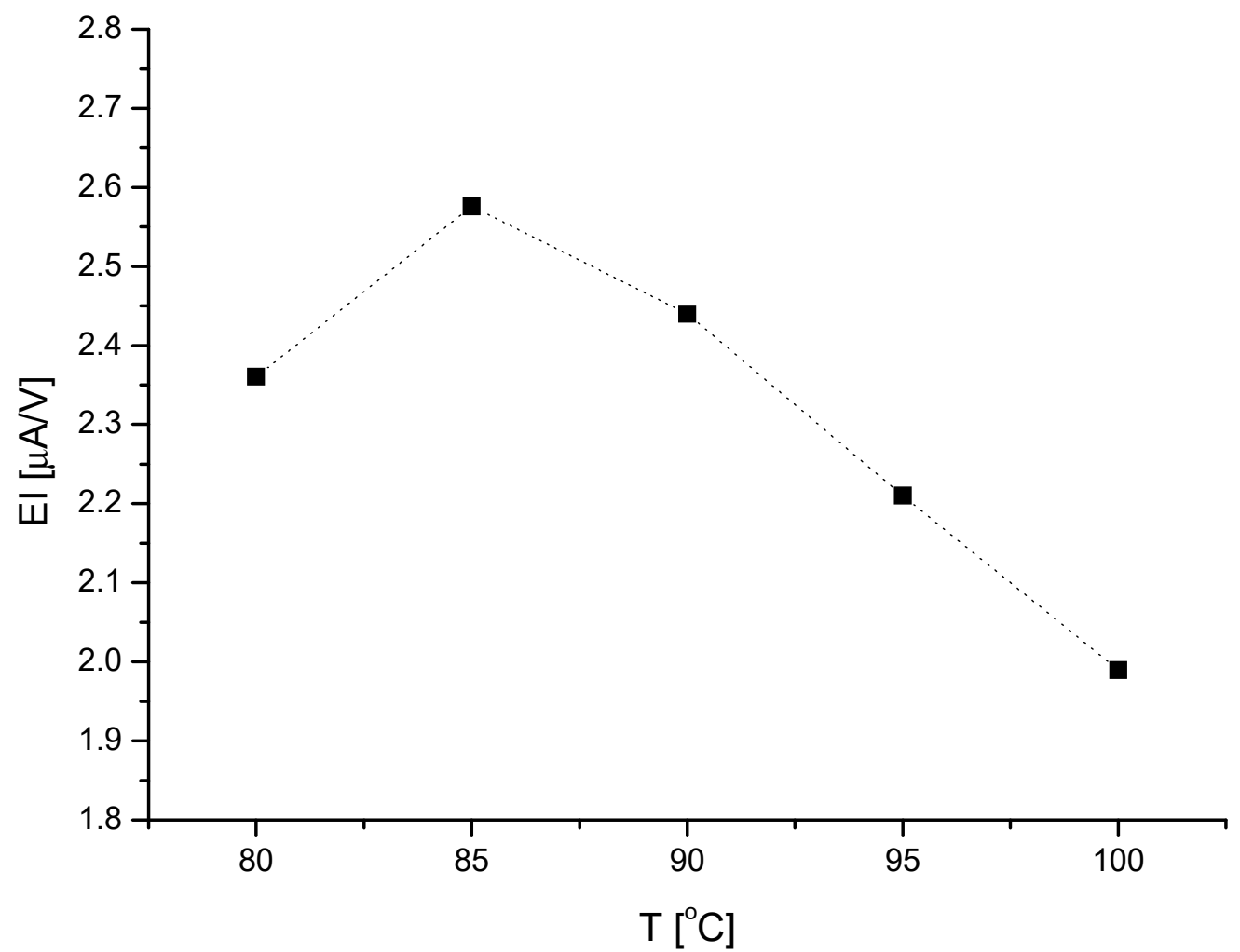

Figure 2. The relationship between the EI value and applied temperature for the extraction of electrochemically active compounds from dried oregano leaves.

\subsection{Antioxidant Activity of Bread with Oregano Extracts}

The antioxidant properties of the prepared bread samples were determined using the FRAP (Ferric Reducing Antioxidant Power) and CUPRAC (Cupric Reducing Antioxidant Capacity) assays. A comparative study of the bread prepared with extract and dried leaves of oregano was carried out; the bread without extract or dried leaves was used as a control. Mean values regarding antioxidant activity are shown in Table 2.

It was found that oregano had a statistically significant effect on the antiradical activity of tested bread as measured by the FRAP and CUPRAC methods. In this study, the FRAP activity of bread extracts ranged from 0.34 to 0.81 , depending on the sample variant. It was found that oregano increased the antioxidant activity of newly prepared bread. The antioxidant activity was proved to be stable during bread storage. The study revealed that the addition of extract from oregano as low as $0.1 \%$ increased the content of compounds with antioxidant activity in extracts made from fresh bread (E1) by more than $72 \%$ (FRAP 
method) and more than 40\% (CUPRAC method) compared to the control sample. For the stored samples (E1S), an increase in redox compounds by more than $123 \%$ (FRAP method) and more than $56 \%$ (CUPRAC method) was determined, respectively, compared to the bread samples without oregano extract. Higher concentration of the extract had no significant effect on the results obtained for the determination of antioxidant content. In contrast, $2 \%$ addition of dried oregano leaves increased antioxidant content by more than 69\% (FRAP method) and more than 65\% (CUPRAC method) for fresh bread samples (L2) and by $100 \%$ (FRAP method) and more than $75 \%$ (CUPRAC method) for bread samples stored for 5 days (L2S). The greatest difference in terms of antioxidant content was observed for stored bread containing 3\% dried oregano (L3S). For these samples, the antioxidant content determined by the FRAP assay increased by more than $138 \%$ and that determined by the CUPRAC assay increased by more than $90 \%$. Oregano in both extract and leaf forms was found to increase the antioxidant activity statistically significantly from bread. However, the results of the study showed a slight decrease in the antioxidant activity of stored bread with a leaf addition greater than $3 \%$ and in the antioxidant activity of fresh bread with the addition of oregano extract at $0.7 \%$ compared to $0.4 \%$. The slight variations in the antioxidant activity of breads can be caused by the baking process, with the blocking of reactive groups of antioxidants (e.g., polyphenols) by bread components, such as wheat, proteins, and starch [19]. However, there were no statistically significant differences in terms of the antioxidant activity of the samples formulated with either oregano extract or leaves.

Table 2. The results of determination of the antioxidant activity of extracts prepared from bread.

\begin{tabular}{ccc}
\hline Sample & $\begin{array}{c}\text { FRAP } \\
\text { Trolox Equ. } \\
(\mathbf{m g} / \mathbf{m L})\end{array}$ & $\begin{array}{c}\text { CUPRAC } \\
\text { Quercetin Equ. } \\
(\mu \mathrm{M} / \mathrm{L})\end{array}$ \\
\hline KC & $0.43^{\mathrm{a}} \pm 0.02$ & $0.47^{\mathrm{a}} \pm 0.02$ \\
\hline E1 & $0.74^{\mathrm{b}} \pm 0.12$ & $0.66^{\mathrm{b}} \pm 0,01$ \\
\hline E2 & $0.77^{\mathrm{b}} \pm 0.01$ & $0.66^{\mathrm{b}} \pm 0.03$ \\
\hline E3 & $0.73^{\mathrm{b}} \pm 0.09$ & $0.61^{\mathrm{b}} \pm 0.01$ \\
\hline L2 & $0.73^{\mathrm{b}} \pm 0.02$ & $0.78^{\mathrm{c}} \pm 0.04$ \\
\hline L3 & $0.77^{\mathrm{b}} \pm 0.07$ & $0.78^{\mathrm{c}} \pm 0.02$ \\
\hline L4 & $0.79^{\mathrm{b}} \pm 0.04$ & $0.77^{\mathrm{c}} \pm 0.08$ \\
\hline KCS & $0.34^{\mathrm{a}} \pm 0.05$ & $0.41^{\mathrm{a}} \pm 0.01$ \\
\hline E1S & $0.76^{\mathrm{b}} \pm 0.03$ & $0.64^{\mathrm{b}} \pm 0.05$ \\
\hline E2S & $0.79^{\mathrm{b}} \pm 0.02$ & $0.62^{\mathrm{b}} \pm 0.08$ \\
\hline E3S & $0.71^{\mathrm{b}} \pm 0.04$ & $0.66^{\mathrm{b}} \pm 0.04$ \\
\hline L2S & $0.68^{\mathrm{ab}} \pm 0.06$ & $0.72^{\mathrm{c}} \pm 0.00$ \\
\hline L3S & $0.81^{\mathrm{c}} \pm 0.01$ & $0.78^{\mathrm{c}} \pm 0.01$ \\
\hline L4S & $0.78^{\mathrm{b}} \pm 0.05$ & $0.75^{\mathrm{c}} \pm 0.04$ \\
\hline
\end{tabular}

Mean value \pm standard deviation $(n=4)$; mean values designated by different lowercase superscript $\left({ }^{\mathrm{a}, \mathrm{ab}, \mathrm{b}, \mathrm{c}}\right)$ and placed in the same column differ statistically $(p \leq 0.05)$.

Some authors also assessed the antioxidant activity of bread enriched with plant raw materials. Sayed et al. [20] showed that the addition of cumin, caraway seeds, and by- product flour can improve the antioxidant potential and overall quality of protein bread. Antioxidant capacity values increased with an increasing fortification level of cumin and caraway flour about two times in comparison with the control bread. Likewise, the antioxidant activity in breads with grape seed extract (GSE) was investigated [21]. The results showed that bread with the addition of GSE had stronger antioxidant activity than that of blank bread and increasing the level of GSE addition further enhanced the 
antioxidant capacity of the bread. This study confirmed that bread enriched with vegetable raw materials, such as oregano, could increase the antioxidant content and allow the production of functional bread.

\subsection{Sensory Evaluation}

Sensory evaluation is an essential component in the development of new products. The sensory features of bread, such as smell, taste, and color, reflect its quality and are important for the consumer's choice. Sensory analysis showed that sweet and sour smell was dominant in both the samples of analyzed bread. The faint smell was felt to a lesser degree, while the grassy and foreign smells were the least noticeable (Figure 3). However, significant differences were found in the smell profile of the tested samples. Fresh bread samples prepared with oregano were characterized by a higher intensity of faint and sweet smell, and the control bread by a sour smell. A slight grassy smell was also noticeable in the oregano-containing bread samples. Statistical analysis of the obtained results showed that despite the differences in the smell, descriptors of the bread prepared without and with the oregano was at a similar level. However, it was found that the sensory qualities of the bread prepared with the addition of leaves changed during storage to a lesser degree compared to the samples prepared with oregano extract. As far as the taste of the samples was concerned, significant differences were found in the case of all the descriptors, except for the faint and foreign tastes, which were noted at low levels that did not differ from each other. Based on the obtained results, it was found that the addition of oregano significantly increased the sense of bitter, sweet, and grassy taste. In the control bread samples, the dominant flavor was salty and sour. A statistically higher score was given for the overall taste desirability of bread with the oregano extract, while in the case of bread prepared with addition of oregano leaves, the score was higher after storage. The color profile of the bread samples prepared with the addition of oregano was found to be changed after storage. Samples prepared with the extract appeared darker than those prepared with leaves, and the color darkened further with storage.

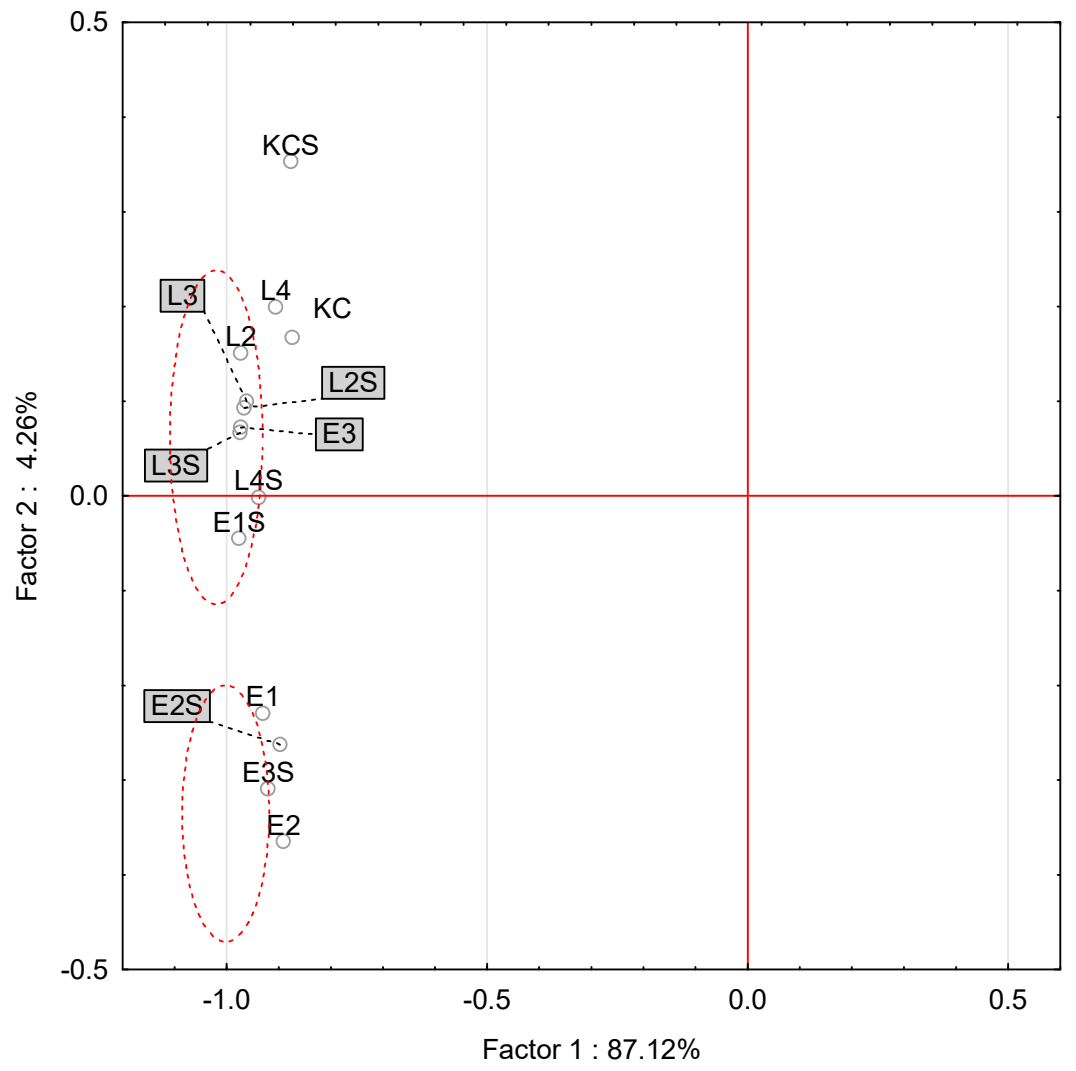

Figure 3. Cont. 


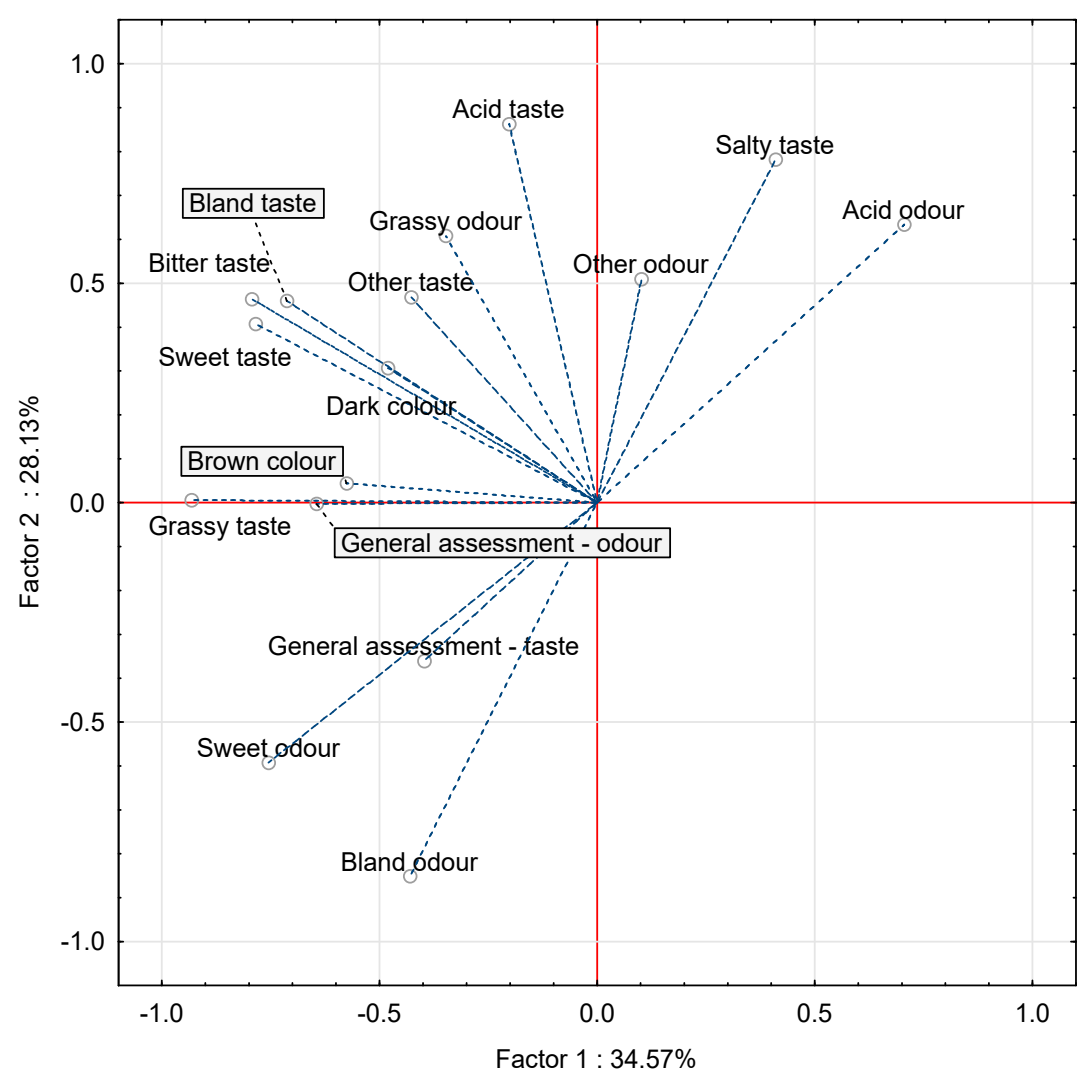

Figure 3. PCA analysis of quality indexes in profile analysis of bread prepared with oregano leaf and oregano leaf extract.

The sensory characteristics such as palatability, texture, and color of food products, including bread, reflect their quality and are important in determining the consumer's choice. In the case of bread products, natural raw materials play a particularly important role, which are often used as additives to enhance their nutritional value [22,23]. The addition of herbs, spices, and extracts from plants such as grapes, soya, rosemary, and barley sprouts, to cereal products and bread is also the most common $[19,20,24-26]$. All these ingredients have a positive influence on the sensory qualities of food. Since oregano extracts can cause a bitter or grassy taste, the influence of their addition on the sensory acceptability of bread was carefully examined in this study. The sense of acidic taste and aroma during the storage, inter alia, was a result of the transformation of ferulic acid released during this period, which was subject to decarboxylation leading to the formation of $p$-vinylguaiacol. PCA projection clearly differentiated the control bread samples and the bread samples prepared with oregano extract and oregano leaves after baking and after 5 days of storage. Data evaluating the effect of the addition of rosemary extract on the sensory quality of bread can be found in the literature. In a study by de Conto et al., it was determined that the addition of more than $2.5 \mathrm{~g}$ of extract was negatively received by the consumers [26]. The bread had a flavor typical for rosemary and a bitter aftertaste. Therefore, other researchers suggested that instead of extracts, ground leaves of raw materials could be used, which was followed in this study with the use of ground oregano leaves in parallel with oregano extract. A similar study on the use of leaves was carried out by Gramza-Michałowska et al., in which the possibility of the application of ground yellow and white tea leaves as a component of cookies was demonstrated [27]. In addition, Przeor and Flaczyk proposed the use of mulberry leaves for cake baking. It should be noted that the influence of the extracts on taste depends on many factors. The type of matrix, or the structure and consistency of the product, is also an important issue [28]. However, taste is more pronounced in the case of products with higher fat content, than in those with lower fat content, and in homogeneous products compared to nonhomogeneous ones [28]. 
The $\mathrm{pH}$ of the product, water content, and specificity of the substance added to enrich the product, for example the extract, are also of importance, with the type and structure of the polyphenols present in the substance playing a key role [29]. On the other hand, changes in the quality of the tested bread that was stored could also depend on the changes in biologically active compounds derived from oregano. Blackening manifested by starch retrogradation and fluctuations in physico-chemical indicators could have influenced the changes related to the decomposition of active compounds and the formation of new ones.

Identification of the descriptors of the bread samples prepared with the addition of oregano allowed a range of characteristics for the new bread product produced in this study to be defined. Its sensory profile was characterized by a combination of a highly desirable acidic and sweet taste and a sweet and sour smell.

\section{Conclusions}

Temperature has a significant effect on the extraction efficiency of compounds with antioxidant activity from plant material. Antioxidants are redox compounds and thus their content can be determined in the studied extracts using electrochemical methods. The electrochemical analysis is fast, low-cost, precise, and characterised by low limits of detection of antioxidant compounds. The Square Wave Voltammetry (SWV) was used in this study for determination of the optimum temperature for extraction of phytochemicals from dried oregano. The SWV is a sensitive measurement technique. Moreover, it is a fast, inexpensive, and low-complexity one. The electrochemical index (EI), which expresses the total antioxidant power of tested extract, was calculated. The extract with the highest EI value was used as a bread additive. At the same time, bread with dried leaves was also made. The determination of compounds with antioxidant activity revealed that both the oregano extract and dried leaves statistically significantly increased the antioxidant activity of the studied extracts extracted from bread. Importantly, the taste and odour of the developed bread with oregano extract or dried oregano leaves was sensory acceptable. The demonstrated antioxidant properties of oregano give it the status of a significant functional food ingredient with broad health-enhancing properties.

Author Contributions: Conceptualization, A.M., M.L. and J.K.-C.; methodology, A.M., M.L. and J.K.-C.; software, A.M.; validation, A.M.; formal analysis, A.M.; investigation, A.M.; resources, A.M.; data curation, A.M., M.L. and J.K.-C.; writing-original draft preparation, A.M.; writing-review and editing, A.M., M.L. and J.K.-C.; visualization, A.M.; supervision, M.L. and J.K.-C.; project administration, M.L. and J.K.-C.; funding acquisition, M.L. and J.K.-C. All authors have read and agreed to the published version of the manuscript.

Funding: This research and the APC were funded by Poznan University of Economics and Business, grant number [51102-23-73]

Institutional Review Board Statement: The study did not require ethical approval.

Informed Consent Statement: Not applicable.

Data Availability Statement: Not applicable.

Conflicts of Interest: The authors declare no conflict of interest.

\section{References}

1. Finkel, T.; Holbrook, N.J. Oxidants, oxidative stress and the biology of ageing. Nature 2000, 408, 239-247. [CrossRef]

2. Mariani, E.; Polidori, M.C.; Cherubini, A.; Mecocci, P. Oxidative stress in brain aging, neurodegenerative and vascular diseases: An overview. J. Chromatogr. B Analyt. Technol. Biomed. Life Sci. 2005, 827, 65-75. [CrossRef]

3. Leyva-Lopez, N.; Gutierrez-Grijalva, E.P.; Vazquez-Olivo, G.; Heredia, J.B. Essential oils of oregano: Biological activity beyond their antimicrobial properties. Molecules 2017, 22, 989. [CrossRef]

4. Lee, C.; Jeong, J.; Kim, H.; Kim, Y. Enhanced superoxide sensitivity in organic field- effect transistor sensors by introducing nanoclay-polyphenol-polymer hybrid sensing channels. J. Hazard Mater. 2019, 374, 159-166. [CrossRef]

5. Giovagnoli-Vicuña, C.; Pizarro, S.; Briones-Labarca, V.; Delgadillo, Á. A Square Wave Voltammetry Study on the Antioxidant Interaction and Effect of Extraction Method for Binary Fruit Mixture Extracts. J. Chem. 2019, 2019, 8706061. [CrossRef] 
6. Nejadmansouri, M.; Majdinasab, M.; Nunes, G.S.; Marty, J.L. An Overview of Optical and Electrochemical Sensors and Biosensors for Analysis of Antioxidants in Food during the Last 5 Years. Sensors 2021, 21, 1176. [CrossRef]

7. Cantalapiedra, A.; Gismera, M.J.; Sevilla, M.T.; Procopio, J.R. Sensitive and selective determination of phenolic compounds from aromatic plants using an electrochemical detection coupled with HPLC method. Phytochem. Anal. PCA 2014, 25, 247-254. [CrossRef] [PubMed]

8. Gazdik, Z.; Reznicek, V.; Adam, V.; Zitka, O.; Jurikova, T.; Krska, B.; Matuskovic, J.; Plsek, J.; Saloun, J.; Horna, A.; et al. Use of liquid chromatography with electrochemical detection for the determination of antioxidants in less common fruits. Molecules 2008, 13, 2823-2836. [CrossRef]

9. Ligaj, M.; Kobus-Cisowska, J.; Szczepaniak, O.; Szulc, P.; Kikut-Ligaj, D.; Mikołajczak-Ratajczak, A.; Bykowski, P.; Szymanowska, D.; Przeor, M.; Polewski, K.; et al. Electrochemical screening of genoprotective and antioxidative effectiveness of Origanum vulgare L. and its functionality in the prevention of neurodegenerative disorders. Talanta 2021, 223, 121749. [CrossRef]

10. Lino, F.M.A.; De Sá, L.Z.; Torres, I.M.S.; Rocha, M.L.; Dinis, T.C.P.; Ghedini, P.C.; Somerset, V.S.; Gil, E.S. Voltammetric and spectrometric determination of antioxidant capacity of selected wines. Electrochim. Acta 2014, 128, 25-31. [CrossRef]

11. Hanafy, D.M.; Prenzler, P.D.; Burrows, G.E.; Ryan, D.; Nielsen, S.; El Sawi, S.A.; El Alfy, T.S.; Abdelrahman, E.H.; Obied, H.K. Biophenols of mints: Antioxidant, acetylcholinesterase, butyrylcholinesterase and histone deacetylase inhibition activities targeting Alzheimer's disease treatment. J. Funct. Foods 2017, 33, 345-362. [CrossRef]

12. Öztürk, M.; Duru, M.E.; Kivrak, S.; Mercan-Doğan, N.; Türkoglu, A.; Özler, M.A. In vitro antioxidant, anticholinesterase and antimicrobial activity studies on three Agaricus species with fatty acid compositions and iron contents: A comparative study on the three most edible mushrooms. Food Chem. Toxicol. 2011, 49, 1353-1360. [CrossRef]

13. Lovrić, M. Square-Wave Voltammetry. In Electroanalytical Methods; Scholz, F., Bond, A.M., Compton, R.G., Fiedler, D.A., Inzelt, G., Kahlert, H., Komorsky-Lovrić, Š., Lohse, H., Lovrić, M., Marken, F., et al., Eds.; Springer: Berlin/Heidelberg, Germany, 2010; pp. 121-145.

14. De Macêdo, I.Y.L.; Garcia, L.F.; Oliveira Neto, J.R.; de Siqueira Leite, K.C.; Ferreira, V.S.; Ghedini, P.C.; de Souza Gil, E. Electroanalytical tools for antioxidant evaluation of red fruits dry extracts. Food Chem. 2017, 217, 326-331. [CrossRef]

15. Onyebuchi, C.; Kavaz, D. Effect of extraction temperature and solvent type on the bioactive potential of Ocimum gratissimum L. extracts. Sci. Rep. 2020, 10, 21760. [CrossRef]

16. Vieira, T.M.F.S.; Shimano, M.Y.H.; da Silva Lima, R.; de Camargo, A.C. Optimization of extraction of antioxidants from aromatic herbs and their synergistic effects in a lipid model system. J. Food Bioac. 2019, 7, 63-72. [CrossRef]

17. Khattak, M.M.A.K.; Abidin, A.Z.; Azahari, N. Ideal extraction temperature for antioxidants from holy basil and bunching onion. Prog. Nutr. 2019, 21, 971-976. [CrossRef]

18. Madureira, J.; Melgar, B.; Santos-Buelga, C.; Margaça, F.M.A.; Ferreira, I.C.F.R.; Barros, L.; Cabo Verde, S. Phenolic Compounds from Irradiated Olive Wastes: Optimization of the Heat-Assisted Extraction Using Response Surface Methodology. Chemosensors 2021, 9, 231. [CrossRef]

19. Świeca, M.; Sęczyk, L.; Gawlik-Dziki, U.; Dziki, D. Bread enriched with quinoa leaves-The influence of protein-phenolics interactions on the nutritional and antioxidant quality. Food Chem. 2014, 162, 54-62. [CrossRef]

20. Sayed Ahmad, B.; Talou, T.; Straumite, E.; Sabovics, M.; Kruma, Z.; Saad, Z.; Hijazi, A.; Merah, O. Protein Bread Fortification with Cumin and Caraway Seeds and By-Product Flour. Foods 2018, 7, 28. [CrossRef]

21. Peng, X.; Ma, J.; Cheng, K.-W.; Jiang, Y.; Chen, F.; Wang, M. The effects of grape seed extract fortification on the antioxidant activity and quality attributes of bread. Food Chem. 2010, 119, 49-53. [CrossRef]

22. Redha, A.A. Review on Extraction of Phenolic Compounds from Natural Sources Using Green Deep Eutectic Solvents. J. Agric. Food Chem. 2021, 69, 878-912. [CrossRef] [PubMed]

23. Dziki, D.; Siastała, M.; Laskowski, J. Evaluation of physical properties of commercial bread. Acta Agrophys. 2011, 18, $235-244$.

24. Ariffin, F.; Baharom, M.A.; Kaur, B.; Murad, M. The Physicochemical Properties and Sensory Evaluation of Bread Made with a Composite Flour from Wheat and Tempoyak (Fermented Durian). Am. J. Appl. Sci. 2015, 12, 775-784. [CrossRef]

25. Bolarinwa, I.F.; Aruna, T.E.; Raji, A.O. Nutritive value and acceptability of bread fortified with moringa seed powder. J. Saudi Soc. Agric. Sci. 2019, 18, 195-200. [CrossRef]

26. De Conto, L.C.; Porto Oliveira, R.S.; Pereira Martin, L.G.; Chang, Y.K.; Steel, C.J. Effects of the addition of microencapsulated omega-3 and rosemary extract on the technological and sensory quality of white pan bread. LWT-Food Sci. Technol. 2012, 45, 103-109. [CrossRef]

27. Gramza-Michałowska, A.; Kobus-Cisowska, J.; Kmiecik, D.; Korczak, J.; Helak, B.; Dziedzic, K.; Górecka, D. Antioxidative potential, nutritional value and sensory profiles of confectionery fortified with green and yellow tea leaves (Camellia sinensis). Food Chem. 2016, 211, 448-454. [CrossRef]

28. Przeor, M.; Flaczyk, E. Antioxidant properties of paratha type flat bread enriched with white mulberry leaf extract. Indian J. Tradit. Knowl. 2016, 15, 237-244.

29. Bayarri, S.; Taylor, A.J.; Hort, J. The Role of Fat in Flavor Perception: Effect of Partition and Viscosity in Model Emulsions. J. Agric. Food Chem. 2006, 54, 8862-8868. [CrossRef] 